\title{
A Hormone and Proteome Approach to Picturing the Initial Metabolic Events During Plasmodiophora brassicae Infection on Arabidopsis
}

\author{
Sylvie Devos, ${ }^{1}$ Kris Laukens, ${ }^{1,2}$ Peter Deckers, ${ }^{1,2}$ Dominique Van Der Straeten, ${ }^{3}$ Tom Beeckman, ${ }^{4}$ \\ Dirk Inzé, ${ }^{4}$ Harry Van Onckelen, ${ }^{1,2}$ Erwin Witters, ${ }^{1,2}$ and Els Prinsen ${ }^{1}$ \\ ${ }^{1}$ Laboratory of Plant Physiology and Plant Biochemistry, University of Antwerp, Groenenborgerlaan 171, B-2020 Antwerp, \\ Belgium; ${ }^{2}$ CEPROMA, Center for Proteome Analysis and Mass Spectrometry, University of Antwerp, Groenenborgerlaan 171, \\ B-2020 Antwerp, Belgium; ${ }^{3}$ Unit Plant Hormone Signaling and Bio-imaging, Department of Molecular Genetics, University \\ of Ghent, K.L. Ledeganckstraat 35, B-9000 Ghent, Belgium; ${ }^{4} \mathrm{VIB}$, Department of Plant Systems Biology, University \\ of Ghent, Technologiepark 927, B-9052 Ghent, Belgium
}

Submitted 13 March 2006. Accepted 3 July 2006.

\begin{abstract}
We report on the early response of Arabidopsis thaliana to the obligate biotrophic pathogen Plasmodiophora brassicae at the hormone and proteome level. Using a $C Y C B 1 ; 1:$ GUS construct, the re-initiation of infection-related cell division is shown from 4 days after inoculation on. Sensitivity to cytokinins and auxins as well as the endogenous hormone levels are evaluated. Both an enhanced cytokinin gene response and an accumulation of isopentenyl adenine and adenosine precede this re-initiation of cell division, whereas an enhanced auxin gene response is observed from 6 days after inoculation on. The alh1 mutant, impaired in the cross talk between ethylene and auxins, is resistant to $P$. brassicae. A differential protein analysis of infected versus noninfected roots and hypocotyls was performed using two-dimensional gel electrophoresis and quantitative image analysis, coupled to matrix-assisted laser desorption ionization time of flight-time of flight mass spectrometrybased protein identification. Of the visualized proteins, $12 \%$ show altered abundance compared with the noninfected plants, including proteins involved in metabolism, cell defense, cell differentiation, and detoxification. Combining the hormone and proteome data, we postulate that, at the very first stages of Plasmodiophora infection, plasmodial-produced cytokinins trigger a local re-initiation of cell division in the root cortex. Consequently, a de novo meristematic area is established that acts as a sink for hostderived indole-3-acetic acid, carbohydrates, nitrogen, and energy to maintain the pathogen and to trigger gall development.
\end{abstract}

Clubroot is an infectious plant disease that affects members of Brassicaceae. This disease is caused by the obligate biotrophic protist Plasmodiophora brassicae Woronin and has devastating effects on Brassica crop yield worldwide. The life cycle of this pathogen can be divided into two phases: a primary phase in which events are confined to the root hairs, and a secondary phase that occurs in the cortex and the stele of the hypocotyl and roots of the infected plants. In the latter phase, abnor-

\section{E. Witters and E. Prinsen shared senior authorship.}

Corresponding author: Els Prinsen; Telephone: +0032-3-265.37.11; Fax: +0032-3-265.34.17; E-mail: els.prinsen@ua.ac.be mal tissue proliferation takes place, leading to the formation of galls. Galls were described as products of cell division and subsequent elongation of the newly formed cells (Ingram and Tommerup 1972).

At an advanced stage in the infection, host plants suffer from permanent wilting, because the galls obstruct the normal water and nutrient transport in the root or destroy the root tissue. The intrinsic characteristics of clubroot disease point to an involvement of plant hormones in clubroot symptom development. A role for cytokinins (Dekhuijzen 1980, 1981; Dekhuijzen and Overeem 1971; Devos et al. 2005; Müller and Hilgenberg 1986) and auxins (Butcher et al. 1974; Devos et al. 2005; GrsicRausch et al. 2000; Kavanagh and Williams 1981; LudwigMüller et al. 1993, 1996, 1999; Mousdale 1981; Neuhaus et al. 2000; Raa 1971) in gall development has been suggested. The availability of Arabidopsis thaliana mutants has been exploited to investigate a set of biochemical and morphological mutant lines that might affect the interaction with $P$. brassicae. In previous experiments, mutants affected in glucosinolate metabolism and altered plant hormone response were screened for a tolerant reaction to clubroot (Ludwig-Müller et al. 1999; Siemens et al. 2002).

Due to its exclusive intracellular life cycle, it remains difficult to distinguish between plant and pathogen genes and the proteins that control the confined phases in the life cycle and disease development. However, some information about proteins involved in $P$. brassicae host's response is available. During $P$. brassicae infection, the expression of a glutaminerich domain (Pyk20) coupled to $\beta$-glucuronidase (GUS) was upregulated (Puzio et al. 2000). Twenty hours after inoculation with $P$. brassicae, the activity of phenylalanine ammonia lyase (PAL) was transiently increased in clubroot-resistant calli (Takahashi et al. 2002). Hansen and associates (1994) investigated a differential protein pattern of control and $P$. brassicae-infected roots at a late stage of infection (4 weeks after inoculation). The overall protein content in the extract of infected roots was higher than in control roots. However, the level of some specific host proteins was reduced in the infected roots (Hansen et al. 1994). Ito and associates (1996) analyzed the protein patterns related to a susceptible and a resistant response in Chinese cabbage roots infected with two different $P$. brassicae isolates, and showed that a protein that was increased in the susceptible response revealed homology to a pathogenesis-related protein. In a previous study, per- 
formed by Ludwig-Müller and associates (1994) on pathogen-related proteins during clubroot disease in roots of a susceptible and a resistant cultivar, a chitinase isoenzyme was induced during the susceptible interaction (Ludwig-Müller et al. 1994).

The proteome is the full complement of proteins expressed by a genome at a specific point in time (Wasinger et al. 1995). An analysis of the protein complement of a biological system, done through protein profiling, provides the opportunity to directly monitor the functional readout of gene expression. Differential proteome expression studies enable us to compare the proteome between systems and have proven to be useful in the search for stress-specific proteins. In Arabidopsis, differential proteome analysis was applied to study salt stress (Lee et al. 2004) and altered secreted proteins in response to salicylic acid (Oh et al. 2005); whereas, to our knowledge, no such analyses were performed on biotic stress in the model plant $A$. thaliana.

This study reports on a combined differential hormone and proteome approach of Arabidopsis roots inoculated with $P$. brassicae, which elicits a susceptible response in Arabidopsis (Colhoun 1958). Because no information is available on initial pathogenic events, this study is focused on the infection stage preceding symptom development.

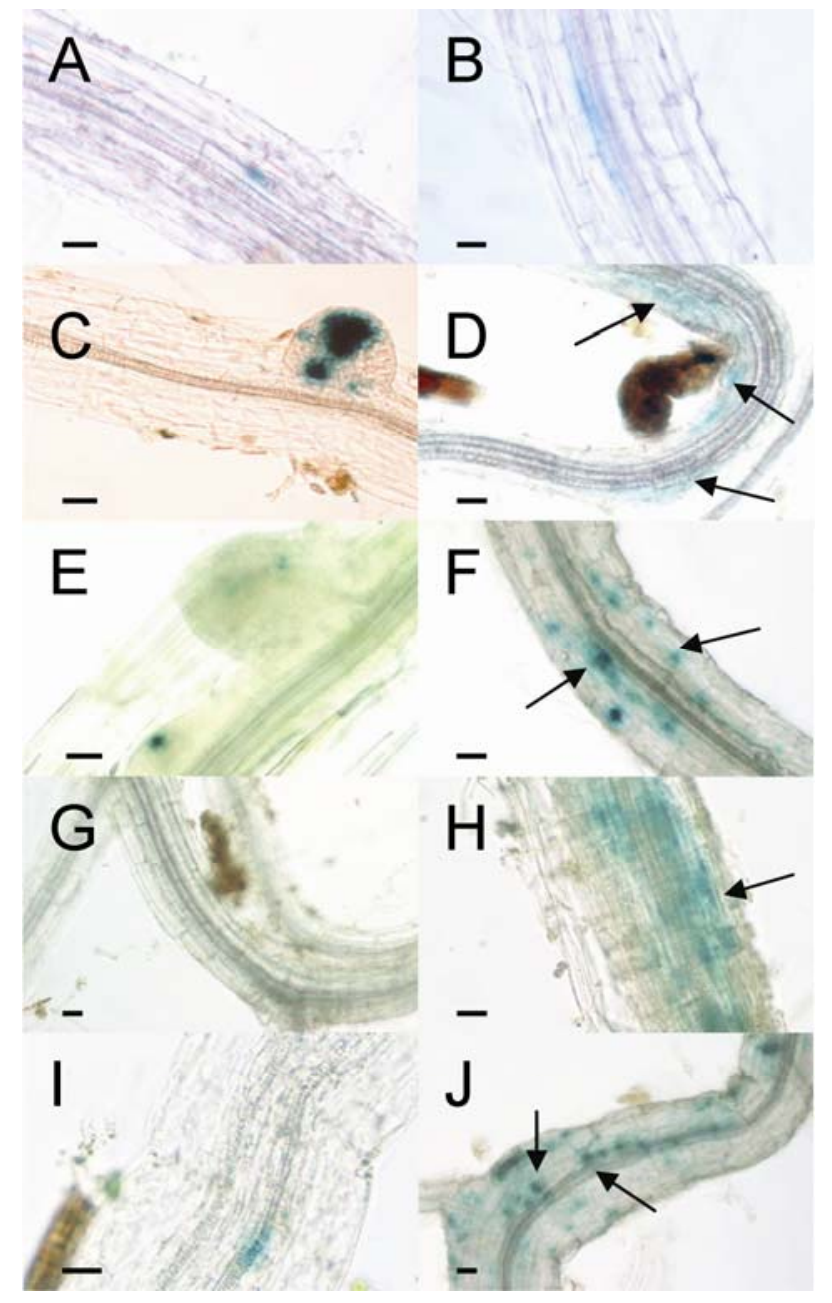

Fig. 1. Histochemical staining of $C Y C B 1 ; 1:: \mathrm{GUS}$ in $\mathbf{A}, \mathbf{C}, \mathbf{E}, \mathbf{G}$, and $\mathbf{I}$, control and $\mathbf{B}, \mathbf{D}, \mathbf{F}, \mathbf{H}$, and $\mathbf{J}$, Plasmodiophora brassicae-infected Arabidopsis thaliana Col-0 roots; $\mathbf{A}$ and $\mathbf{B}, 3$ days after inoculation (DAI); $\mathbf{C}$ and D, 4 DAI; $\mathbf{E}$ and $\mathbf{F}, 5 \mathrm{DAI} ; \mathbf{G}$ and $\mathbf{H}, 8 \mathrm{DAI}$; and $\mathbf{I}$ and $\mathbf{J}$, 10 DAI. Arrow indicates P. brassicae-related cell division. Scale bar $=$ $100 \mu \mathrm{m}$.

\section{RESULTS}

\section{Cell division re-initiation is the first sign of clubroot development.}

The cell division reporter plant $C Y C B 1 ; 1:: G U S$ (ColónCarmona et al. 1999) is used to describe renewed cell division as a marker for the onset of clubroot symptom development. Because $P$. brassicae spores are unable to infect their hosts in vitro, the Arabidopsis plants were grown in soil. In the first 3 days after inoculation (DAI), no difference in the $C Y C B 1 ; 1:$ : GUS expression patterns could be observed between infected plants and control plants. GUS staining was strictly limited to the meristematic areas of the root (Fig. 1A and B). At 4 DAI, additional patches of GUS labeling were apparent in the cortex of differentiated areas of the infected roots (Fig. 1D); whereas, in the control plants, labeling was restricted to meristematic zones of the root (Fig. 1C). At 5 DAI, individual cortex, epidermis, and endodermis cells along the infected root were stained (Fig. 1F), whereas this staining was not observed in the control roots (Fig. 1E). With the progression of clubroot disease (8 and 10 DAI), more cells in all cell layers of the infected roots and hypocotyl were labeled (Fig. $1 \mathrm{H}$ and $\mathrm{J}$ ). The staining patterns observed in the infected roots were different from GUS staining in meristematic areas and never were visualized in the control roots (Fig. $1 \mathrm{G}$ and I). For this reason, we conclude that the enhanced cell division activity is a consequence of the secondary infection caused by $P$. brassicae.

\section{Isopentenyl-type cytokinins accumulate during the onset of $P$. brassicae infection.}

The endogenous levels of cytokinins and auxins were measured and compared between control and infected A. thaliana root and hypocotyl at 4 DAI (Table 1). The level of isopentenyl adenine (iP) was twofold higher in the infected plants than in the control plants. In the control plants, the level of isopentenyl adenosine (iPA) was below the limit of detection $( \pm 100$ fmol), whereas measurable amounts of this active cytokinin were observed in the infected plants. No statistical differences were observed comparing the level of other cytokinin metabolites-zeatin, dihydro zeatin (DHZ), zeatin- $\mathrm{N}^{9}$-glucosides (Z$\mathrm{N}-\mathrm{G})$, zeatin riboside (ZR), dihydro zeatin riboside (DHZR), dihydro zeatin- $\mathrm{N}^{9}$-glucosides (DHZ-N-G), zeatin riboside monophosphate (ZR-P), dihydro zeatin riboside monophosphate (DHZR-P), isopentenyl adenine $\mathrm{N}^{9}$-glucoside (iP-G), and isopentenyl adenosine monophosphate (iPA-P) — between control and infected plants at 4 DAI. At this stage, no differences in the level of indole-3-acetic acid (IAA) and IAA-conjugates between infected and control plants were noticed.

Table 1. Plant hormone levels of control and infected Arabidopsis thaliana Col-0 measured 4 days after inoculation

\begin{tabular}{|c|c|c|}
\hline \multirow[b]{2}{*}{ Hormone compound } & \multicolumn{2}{|c|}{ Levels $\left(\mathrm{pmol} \mathrm{g}^{-1}\right.$ fresh weight) ${ }^{\mathrm{a}}$} \\
\hline & Control & Infected \\
\hline Zeatin (Z) & $0.35 \pm 0.34$ & $0.82 \pm 0.34$ \\
\hline Dihydro Z & $\mathrm{BD}$ & $\mathrm{BD}$ \\
\hline Z-N ${ }^{9}$-glucosides & $\mathrm{BD}$ & $\mathrm{BD}$ \\
\hline$Z$ riboside & $\mathrm{BD}$ & $\mathrm{BD}$ \\
\hline Dihydro (DH) Z riboside & $\mathrm{BD}$ & $\mathrm{BD}$ \\
\hline DH Z-N ${ }^{9}$-glucosides & BD & BD \\
\hline $\mathrm{Z}$ riboside monophosphate & $1.29 \pm 0.27$ & $0.80 \pm 0.27$ \\
\hline $\mathrm{DH} \mathrm{Z}$ riboside monophosphate & $\mathrm{BD}$ & $\mathrm{BD}$ \\
\hline Isopentenyl (iP) adenine & $0.68 \pm 0.31 *$ & $1.52 \pm 0.31 *$ \\
\hline iP adenine $\mathrm{N}^{9}$-glucoside & $\mathrm{BD}$ & $\mathrm{BD}$ \\
\hline iP adenosine & $\mathrm{BD} *$ & $0.88 \pm 0.29 *$ \\
\hline iP adenosine monophosphate & $1.04 \pm 0.20$ & $1.23 \pm 0.19$ \\
\hline Indole-3-acetic acid (IAA) & $6.0 \pm 0.5$ & $6.2 \pm 0.5$ \\
\hline IAA conjugates & $10.7 \pm 0.3$ & $11.4 \pm 0.4$ \\
\hline
\end{tabular}

${ }^{\mathrm{a}} \mathrm{BD}=$ below detection limit $( \pm 100 \mathrm{fmol}), n=3, *=P<0.05$. 


\section{$P$. brassicae enhances the expression of cytokinin- and auxin-inducible promoters.}

With the ARR5::GUS construct (D'Agostino et al. 2000), cytokinin responsiveness was visualized during the course of early clubroot disease. In the first 2 DAI, cytokinin response was observed along the pericycle and in vascular tissue (Fig. $2 \mathrm{~A}$ and $\mathrm{B}$ ) in control roots and in infected roots. At 3 DAI, ARR5-directed GUS activity was induced in the cortex and vascular tissue of the infected root and hypocotyl (Fig. 2D), whereas this was not observed in control plants of the same age (Fig. 2C). From 5 DAI on, this activity was observed in all cell layers of the infected root and hypocotyl (Fig. 2F). The entire hypocotyl and upper part of the root system of the infected plants was stained, starting from 10 DAI (Fig. 2H). GUS labeling was not observed in the corresponding areas of the control roots of the same age (Fig. 2E and G).

Using the synthetic DR5 auxin response element coupled to GUS (Ulmasov et al. 1997), auxin responsiveness in the $A$. thaliana Col-0 background was monitored to test the involvement of auxin in early clubroot development. In the first 4 DAI, auxin-directed GUS activity was visible along the vascular tissue in control plants and infected DR5 plants. The signal was specifically high in the pericycle at the site of lateral root development and in the root tips of the main root and lateral roots (Fig. 2I and J). At 5 DAI, additional GUS labeling was observed in individual epidermis cells of the infected roots (Fig. 2L), whereas this response was absent at the corresponding place in the control roots (Fig. 2K). At 6 and 7 DAI, strong DR5::GUS activity was observed at various locations in the cortex of the roots and hypocotyl of infected plants (Fig. $2 \mathrm{~N}$ and $\mathrm{O}$ ). Control plants of these ages showed no auxin responsiveness at the corresponding sites (Fig. 2M and O). Starting from 10 DAI, high GUS signals were detected throughout all cell layers of the hypocotyl and the first centimeter of the root, near the crown of the plant (Fig. 2R). In the control roots, auxin-related GUS staining localized only in meristematic areas of the plant and in vascular tissue (Fig. 2Q).

\section{The alh1 mutant shows a resistant response toward $P$. brassicae.}

The alh 1 mutant has a defect in the cross talk between ethylene and auxins, probably at the site of auxin transport. This mutant shows a resistant phenotype upon $P$. brassicae infection. At $32 \mathrm{DAI}$, the infection ratio of $A$. thaliana Col-0 is $92.5 \pm$ $3.3 \%$, whereas the infection ratio of the alh 1 mutant is $30 \pm$ $5.7 \%$. Although the infection ratio is three times lower in the mutant, the plants that are infected have symptom progression similar to that of the wild-type plants. At 32 DAI, the hypocotyl is twice as thick as the hypocotyl of noninfected plants, galls are formed on the upper root system, and a red or purple color is observed in the infected stem of this mutant. In the infected wild-type plants, leaf-like outgrowths, known as teratoma, sprouted from the rosette. This was not observed in the infected alh1 mutant (Fig. 3).

To test whether the disease phenotype could be rescued by auxin, naphthalene acetic acid (NAA) was added to the alh1 mutant. At 32 DAI, the infection ratio of A. thaliana Col-0 was

Fig. 2. A to $\mathbf{H}$, Histochemical staining of ARR5::GUS in control (A, C, E, and $\mathbf{G})$, and Plasmodiophora brassicae-infected (B, D, F, and $\mathbf{H})$ Arabidopsis thaliana Col-0 roots. A and B, 2 days after inoculation (DAI); $\mathrm{C}$ and D, 3 DAI; E and F, 5 DAI, and G and H, 10 DAI. Scale bar $=100$ $\mu \mathrm{m}$. I to R, Histochemical staining of DR5::GUS in control (I, K, M, O, and $\mathbf{Q}$ ) and Plasmodiophora brassicae-infected (J, L, N, P, and $\mathbf{R}$ ) Arabidopsis thaliana Col-0 roots. I and J, 3 DAI; K and I, 5 DAI; $M$ and N, 6 DAI; O and P, 7 DAI, and Q and R, 10 DAI. Scale bar $=100 \mu \mathrm{m}$.

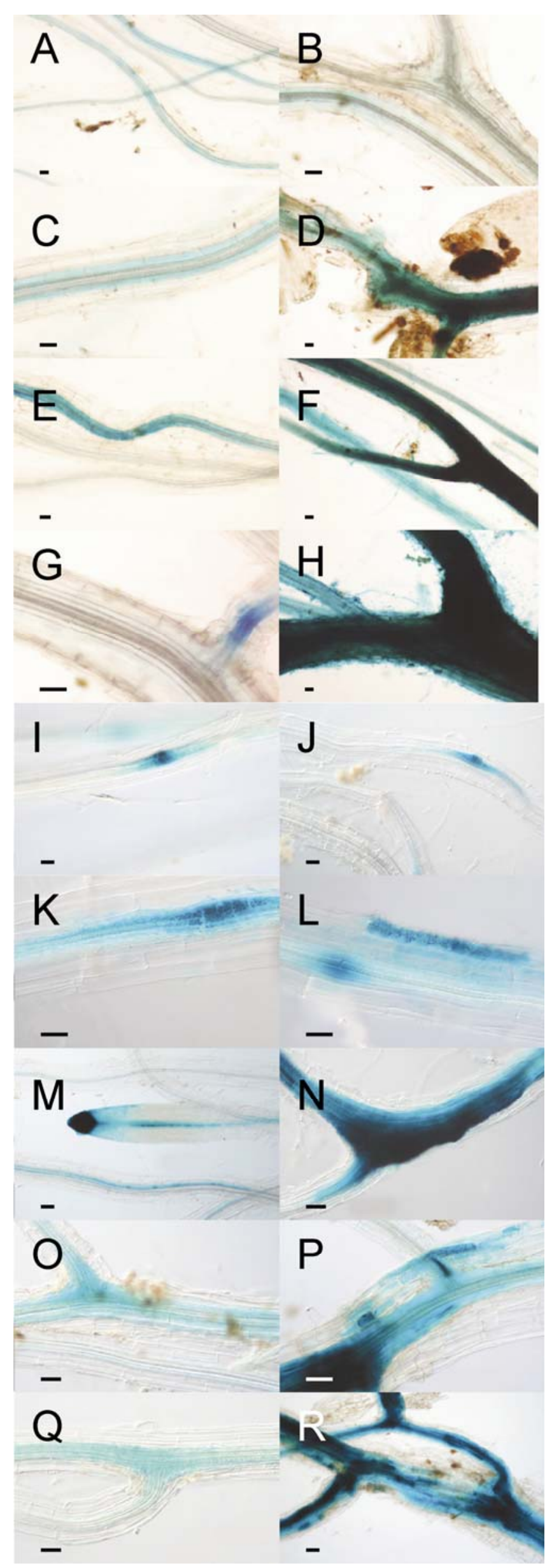

Vol. 19, No. 12, $2006 / 1433$ 
$100 \pm 0 \%$, whereas the infection ratio of the alh 1 mutant was $25 \pm 12 \%$.

\section{Differentially regulated proteins during $P$. brassicae infection are mainly involved in plant defense and metabolism.}

The protein pattern of $P$. brassicae-infected A. thaliana roots and hypocotyls at 4 DAI was compared with the protein pattern of noninfected A. thaliana roots and hypocotyls of the same age using two-dimensional gel electrophoresis analysis (2DGE). The experiment was performed in triplicate, and each independent sample consisted of a pool of approximately 250 explants. Of $390 \pm 42$ spots, 46 spots (of which the average "percentage volume" varied with a ratio of 1.5 between control and infected samples) were selected as differentially abundant proteins. These spots are indicated on the gels presented in Figure 4. Among them, 35 were upregulated (more intense or only present in the gels of the infected plants) (Fig. 4A), whereas 11 spots were downregulated (more intense or only present in the control samples) (Fig. 4B).

Proteins that were significantly up- or downregulated were isolated and prepared for analysis by matrix-assisted laser desorption ionization (MALDI) time of flight (TOF) and identified using probability-based scoring algorithms by querying public databases. The two-dimensional reference map and proteins identified in this study can be accessed online at the University of Antwerp-Centre for Proteome Analysis website. The protein score threshold confidence interval percentage was 99.99\%. All proteins identified in this study were A. thaliana proteins. The observed molecular mass and isoelectric point (pI) of the proteins on the gel corresponded with the predicted molecular mass and $\mathrm{pI}$ of these proteins. However, there were two exceptions. The observed molecular mass of pectin methylesterase (spot 6) and of peroxiredoxin (spot 41) differed significantly from the predicted molecular mass. We detected only sequence homology with the N-terminal part of both proteins. All differentially expressed proteins are listed in Table 2. From each protein, we registered the MIPS (Munich Information Center for Protein Sequences) functional categories (Fun-
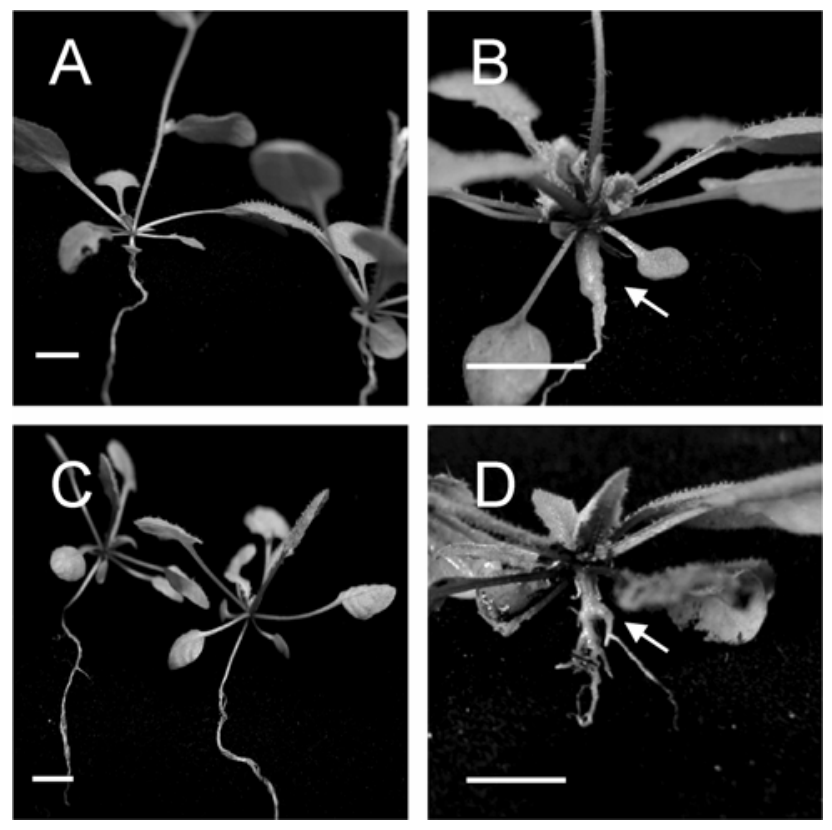

Fig. 3. A, Noninfected plants and B, Plasmodiophora brassicae-infected Arabidopsis thaliana Col-0 32 days after inoculation and $\mathbf{C}$, noninfected plants and D, A. thaliana alh 132 days after inoculation. Arrows indicate the enlarged hypocotyl of the infected plants. Scale bar $=1 \mathrm{~cm}$.
Cat) indicating the functional activity of the protein (Schoof et al. 2002), as well as the ratio of abundance, the accession and locus number, and a description or name of the protein. All differentially regulated proteins could be categorized into 11 functional classes.

Of all proteins differentially regulated upon clubroot infection, 7\% were involved in general metabolism (MIPS FunCat 1). Adenosine kinase (ADK; spot 39) was downregulated, whereas methionine synthase (spot 20) and the $S$-adenosylhomocysteine (SAH) hydrolase (spot 17) were upregulated upon infection.

Four spots $(9 \%)$ corresponded to proteins that are related to energy metabolism (MIPS FunCat 2): the ribulose biphosphate carboxylase large chain (RuBisCo LSU) of $A$. thaliana (spot 4); two upregulated dehydrogenases, a putative dehydrogenase E1a-like subunit, known as IAR4 (spot 23) and the dihydrolipoamide dehydrogenase precursor (spot 28); and the fructosebisphosphate aldolase (spot 42), the only one downregulated after infection.

The second largest functional class $(26 \%)$ contained differentially regulated proteins involved in cell rescue, defense, and virulence (MIPS FunCat 32). Six of these proteins (spots 1, 2, 7, 9,12 , and 21) corresponded to myrosinase. Spots 1, 2, 12, and 21 were highly upregulated during infection; whereas, in the control setup, these proteins were almost absent. In A. thaliana, there are three myrosinase genes. For two of these, the active gene transcripts have been described (Xue et al. 1995). The proteins encoded by both transcripts were detected in this study. We observed the appearance of multiple spots that are the product of the same gene, which suggests that post-translational modifications of these proteins had occurred. Spot 18 encodes a myrosinase-binding protein that is also known as a jasmonate-inducible protein, jacalin, or a putative lectin. The myrosinase-binding protein is a protein of unknown function (MIPS FunCat 99). The other six proteins of this functional category were shown to be involved in the detoxification of reactive oxygen species (ROS): catalase3 (cat3, spot 8), glutathione $S$-transferase (GST, spot 16), ferredoxin-nitrite reductase (spot 24), thioredoxine (spot 33), disulfide isomerase (spot 37), and peroxiredoxin (spot 41). All proteins, except the latter two, were upregulated.

Of the differentially abundant proteins, $9 \%$ were categorized under cell architecture: tubulin $\beta 4$, tubulin $\alpha$, tubulin $\beta-1,4$, and tubulin $\beta-2,3$; (spots 38, 40, 44, and 45 respectively; MIPS FunCat 40.02 and 70.04). It is striking that all these tubulins were downregulated during $P$. brassicae infection.

Four spots $(9 \%)$ corresponded to a putative classification (MIPS FunCat 98). Spots 3 and 19 were major latex proteins. The hypothetical nuclear RNA binding protein was upregulated twice in different spots of the infected roots (spots 27 and 31 ). Both spots have a different pI, presumably due to posttranslational modifications or the occurrence of isoforms of this protein.

The largest class (28\%) represented proteins of unknown function (MIPS FunCat 99). Two of these proteins were upregulated during infection and could be related to cell wall architecture: pectin methylesterase (spot 6) and polygalacturonase inhibiting protein 1 (PGIP1; spot 13). Other proteins of unknown function that were upregulated in clubroot-infected plants include the cysteine proteinase inhibitors or cystatin (spot 14), the putative RNA-binding protein with similarity to the polyadenylate binding protein 5 (spot 25), a putative glyoxalase (spot 26), the 4-aminobutyrate aminotransferase (GABA transaminase, spot 29), a putative ATP synthase (32), a putative transcription factor (spot 34), a hypothetical protein (spot 30), and a MutT/nudix family protein (spot 35). Two proteins were downregulated during clubroot disease: a putative $60 \mathrm{~S}$ acidic ribosomal protein P0 (spot 46) and a putative heat shock protein (spot 36). 
Four classes, consisting of one protein each, were involved in protein metabolism: a proteasome $20 \mathrm{~S} \beta$-subunit (spot 43) was downregulated during infection and has a function in protein degradation (MIPS FunCat 4). A putative GTP-binding protein (spot 11), a cytosolic cyclophilin ROC3 (spot 15), and elongation factor EF-2 (spot 22) were "protein with binding function" (MIPS FunCat 16), "protein fate" (MIPS FunCat 14), and "translation" (MIPS FunCat 12.04), respectively. The latter proteins were upregulated in infected tissue. Two proteins $(4 \%)$ have a function in cellular transport (MIPS FunCat 20). Spot 5 was a GTP-binding nuclear protein from the RAN1 gene of $A$. thaliana. Spot 10 was a putative porin of plastid membranes.

\section{DISCUSSION}

Cytokinins and auxins involved

in induced cell division upon $P$. brassicae infection.

This study describes the combination of both a hormone and a proteome approach to reveal metabolic events that regulate the initiation of clubroot disease in Arabidopsis. We focused specially on early stages of infection that precede symptom development. This information is biologically relevant and crucial in order to understand the cause of gall formation in susceptible hosts. Therefore, a kinetic study was performed using the reporter constructs $C Y C B 1 ; 1:: G U S$, ARR5::GUS, and DR5::GUS. Upon $P$. brassicae infection, an altered cytokinin response was observed that started from 3 DAI. From 4 DAI, we found an altered cyclinB1 response, followed by an altered auxin response at 6 DAI. Müller and Hilgenberg (1986) showed that isolated plasmodia (isolated from roots $23 \mathrm{DAI}$ ) could take up ${ }^{14} \mathrm{C}$-adenine in vitro and eventually incorporate it into trans-zeatin. Therefore, it was concluded that plasmodia could at least partially synthesize cytokinins. In this work, we show a cytokinin response in the infected tissue as the first sign of infection. Moreover, it is possible that the isopentenyltype cytokinins trigger this response, because only the active cytokinins iP and iPA show a statistically higher level in infected plants compared with control plants. These cytokinins

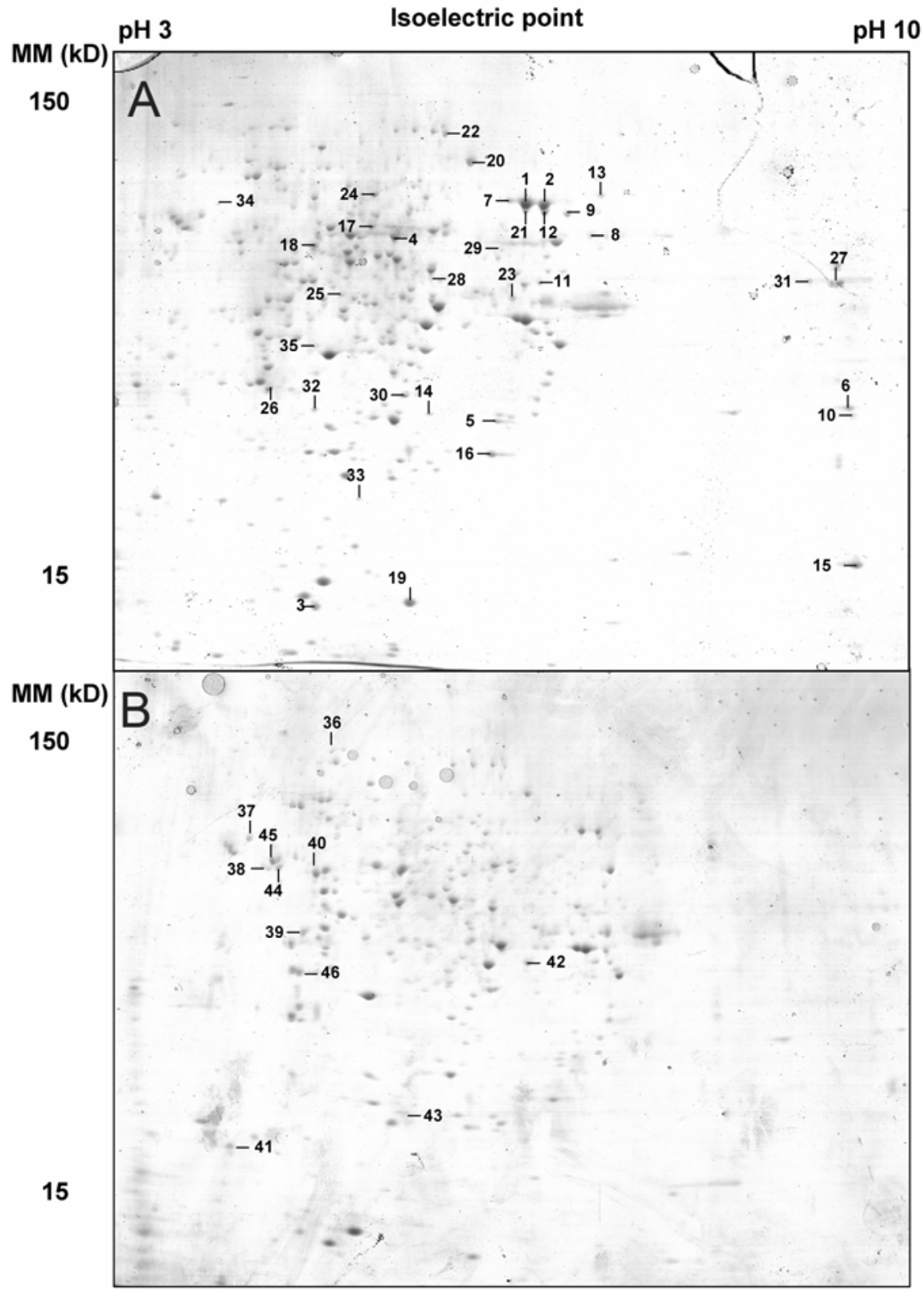

Fig. 4. Two-dimensional electrophoresis map of A, Plasmodiophora brassicae-infected and B, control Arabidopsis thaliana Col-0 roots at 4 days after inoculation. The proteins were visualized by Coomassie Brilliant Blue staining. The numbers correspond with proteins whose abundance changed with a ratio of 1.5 and more upon P. brassicae infection. Molecular mass (MM) in kilodaltons (kD). 
are believed to be important microbial cytokinins (Mok and Mok 2001). None of the other cytokinin metabolites differed in level between control and infected plants. These are all indications that the cytokinins we observe originate from $P$. brassicae. Increased levels of cytokinins in susceptible hosts may be beneficial for the growth of the pathogen (Angra-Sharma and Sharma 1999). We presume that, for this reason, P. brassicae also synthesizes cytokinins. A recent study by Ando and associates (2005) confirmed our observations because it was shown that the upregulation of isopentenyl transferase (IPT) 1, 3, 5, and 7 of Chinese cabbage contributes to the primary development of clubroot. The areas in which the expression of the IPT genes was stimulated transiently developed into galls at a later stage (Ando et al. 2005). Moreover, we show here a consecutive re-initiation of cell division at the site of infection. This indicates the establishment of a new meristem. It remains largely unknown how plants control the reactivation of the cell cycle during development; however, it generally is accepted that plant hormones may play a central role (Stals and Inzé 2001). Himanen and associates (2002) also described the involvement of auxin in the initiation of early lateral root formation. Mothes and Engelbrecht (1963) discovered the potential of cytokinins to induce a metabolic sink in plants. The meristem that possibly is induced by cytokinins that originate from $P$. brassicae might act as a sink for auxin. We found a higher auxin response in the infected tissue from 6 DAI. The fact that no different IAA level is found at 4 DAI coincides with this observation. In addition, we noticed that the alh 1 mutant was resistant toward clubroot. This mutant had a defect in the cross talk between ethylene and auxins, probably at the level of auxin transport (Vandenbussche et al. 2003). It is plausible that this mutant was resistant toward $P$. brassicae because host IAA transport was hampered. Hence, we hypothesize that, in this mutant, IAA cannot reach the site of infection and, therefore, is unable to induce gall development. The addition of NAA to the alh1-infected plants did not rescue the mutant's phenotype. However, the infected wild-type plants showed an increased infection rate with NAA. With this, we assume that NAA is not able to reach the site of infection in the alh 1 mutant. This underlines the necessity of proper IAA transport in order to obtain gall formation.

Table 2. Identification of proteins demonstrating significant relative abundance level changes during Plasmodiophora brassicae infection (ratio $>|1.5|)^{\mathrm{a}}$

\begin{tabular}{|c|c|c|c|c|c|}
\hline MIPS FunCat ${ }^{\text {b }}$ & Ratio & Accession & Locus & Description & Spot \\
\hline 1 & 4.1 & Q8LE20 & At4g13940 & S-adenosyl homocysteinase & 17 \\
\hline 1 & 2.0 & Q6KCR2 & At5g17920 & Cobalamin-independent methionine synthase & 20 \\
\hline 01.03 .01 & -1.8 & Q9LZG0 & At5g03300 & Adenosine kinase 2 & 39 \\
\hline 2 & 5.5 & gi|30421658 & AtCg00490 & RuBisCO large subunit & 4 \\
\hline 2 & 1.5 & Q8H1Y0 & At1g24180 & Dehydrogenase E1a-like subunit (IAR4) & 23 \\
\hline 2 & 1.5 & Q9M5K3 & At1g48030 & Lipoamide dehydrogenase precursor & 28 \\
\hline 02.01 & -2.0 & Q9ZU52 & At2g01140 & Fructose biphosphate aldolase & 42 \\
\hline 32 & 7.3 & O24433 & At3g09260 & Myrosinase & 1 \\
\hline 32 & 7.8 & Q75L84 & At3g09260 & Myrosinase & 2 \\
\hline 32 & 7.8 & O24433 & At3g09260 & Myrosinase & 7 \\
\hline 32.07 & 8.0 & Q96350 & At1g20620 & Catalase (cat3) & 8 \\
\hline 32 & 19.1 & Q9C8Y9 & Atlg66280 & Myrosinase & 9 \\
\hline 32 & 6.1 & O23656 & At1g66270 & Myrosinase & 12 \\
\hline 32.07 & 1.6 & $\mathrm{O} 23626$ & At2g30860 & Glutathione S-transferase & 16 \\
\hline 32 & 11.6 & Q9SR37 & At3g09260 & Myrosinase & 21 \\
\hline 32.07 & 3.5 & Q42957 & At2g15620 & Ferredoxin-nitrite reductase & 24 \\
\hline 32.07 & 2.7 & gi||11134159 & At1g77510 & Thioredoxin & 33 \\
\hline 32.07 & -3.7 & Q6JAC2 & At1g21750 & Disulfide isomerase precursor & 37 \\
\hline 32.07 & -15.7 & Q949U7 & At3g52960 & Peroxiredoxin & 41 \\
\hline 40.02 & -3.6 & Q9M4R9 & At5g44340 & $\beta$-Tubulin 4 & 38 \\
\hline 40.02 & -5.6 & Q39412 & At5g44340 & Tubulin $\beta-1 /-4$ chain & 44 \\
\hline 40.02 & -5.1 & Q39808 & At5g62700 & Tubulin $\beta-2 / \beta-3$ chain & 45 \\
\hline 70.04 & -9.2 & Q9M3T2 & At4g14960 & $\alpha$-tubulin & 40 \\
\hline 98 & 32.5 & Q9ZVF3 & At2g01520 & Major latex protein & 3 \\
\hline 98 & 1.9 & Q9SUR0 & At4g23670 & Major latex protein & 19 \\
\hline 98 & 16.4 & Q9LVT8 & At5g47210 & Hypothetical protein & 27 \\
\hline 98 & 6.6 & Q9LVT8 & At5g47210 & Hypothetical protein & 31 \\
\hline 99 & 16.9 & Q94C39 & At1g11580 & Pectin methylesterase & 6 \\
\hline 99 & 3.5 & Q6PNZ2 & At5g06860 & Polygalacturonase inhibiting protein 1 (PIPG1) & 13 \\
\hline 99 & 4.0 & Q8HOX6 & At5g12140 & Putative cysteine protease inhibitor & 14 \\
\hline 99 & 7.2 & O04317 & At3g16400 & Myrosinase binding protein & 18 \\
\hline 99 & 7.0 & Q9FPJ8 & At5g54900 & Putative RNA-binding protein & 25 \\
\hline 99 & 1.6 & Q940A4 & Atlg11840 & Putative lactoylgluthathione lyase & 26 \\
\hline 99 & 2.5 & Q9LIE2 & At3g22200 & Putative aminobutyrate aminotransferase & 29 \\
\hline 99 & 3.0 & Q94EG6 & At5g02240 & Hypothetical protein & 30 \\
\hline 99 & 2.3 & gi|21592716 & At2g21870 & Putative ATP synthase & 32 \\
\hline 99 & 4.1 & Q9CAT7 & At1g73230 & Putative transcription factor BTF3 & 34 \\
\hline 99 & 2.8 & Q9SU14 & At4g12720 & A MutT/nudix family protein & 35 \\
\hline 99 & -3.3 & Q96269 & At1g79930 & Heat shock protein70 & 36 \\
\hline 99 & -7.9 & Q8LCI7 & At2g40010 & Putative $60 \mathrm{~S}$ acidic ribosomal protein $\mathrm{P} 0$ & 46 \\
\hline 4 & -1.9 & $\mathrm{O} 23716$ & At4g31300 & $20 \mathrm{~S}$ proteasome $\beta$ subunit $\mathrm{A}$ & 43 \\
\hline 12.04 & 1.6 & Q9ASR1 & At1g56070 & Elongation factor EF-2 & 22 \\
\hline 14 & 23.3 & gi|21592448 & At2g16600 & Cytosolic cyclophilin ROC3 & 15 \\
\hline 16 & 5.2 & Q8LDR5 & At1g30580 & Putative GTP-binding protein & 11 \\
\hline 20 & 25 & P41916 & At5g20010 & GTP-binding protein RAN1A & 5 \\
\hline 20.03 & 7.9 & gi|21537313 & At5g67500 & Putative porin & 10 \\
\hline
\end{tabular}

${ }^{a}$ Positive ratio values indicate higher protein abundance in infected plants as compared with noninfected plants, whereas negative values indicate the opposite.

${ }^{b}$ MIPS Functional Categories (Schoof et al. 2002). 
All three reporter constructs showed higher responsiveness in the cortex of plants starting from 3 to 6 DAI. This clearly indicates that the infected plants reached the secondary infection of the cortex. At 3 DAI, no signs of re-initiation of cell division in the root cortex were apparent (Fig. 1). At 4 DAI, however, we noticed cell division at various places in the root cortex of infected plants that clearly were different from the initiation of lateral root formation. Lateral root initiation starts in the pericycle of the root (Himanen et al. 2002); whereas, in our case, cortex cells clearly were dividing. Moreover, the multitude of cells that were dividing in the vicinity of each other points to a renewed cell division other than lateral root initiation. Therefore, we conclude that this cell division is due to $P$. brassicae secondary infection. In previous reports on clubroot disease in A. thaliana, the secondary infection initiated at 20 DAI (Mithen and Magrath 1992). The discrepancy between these and our observation can be a result of the specific strain of $P$. brassicae spores that was used. Moreover, it remains plausible that only a few cells reached the secondary infection at 4 DAI. At later time points, more GUS staining was noticed; therefore, we can presume that more cells of the infected plants progressed to the secondary infection.

\section{Differential protein expression induced by $\boldsymbol{P}$. brassicae.}

To support the above theory and to expose other metabolic events that take place during early symptom development upon $P$. brassicae infection, a differential proteome analysis was performed in Arabidopsis at 4 DAI. This was shown to be the period at which the first symptoms (e.g., cell division re-initiation) were observed in the infected roots. Because the entire host root system plus hypocotyl were included in this study, the amount of infected cells certainly was less than $1 \%$. At 4 DAI, only a few cells were infected, as was shown using the CYCB1;1::GUS, ARR5::GUS, and DR5::GUS constructs. The dilution that occurred in that way enhances the impact of the differentially regulated proteins at the level of the infected versus noninfected cells. The proteome data are discussed further in view of their function in clubroot disease and compared with other studies on abiotic or biotic stress in higher plants.

\section{Metabolism.}

Three proteins (ADK, methionine synthase, and SAH hydrolase) that regulate the level of $S$-adenosylmethionine (SAM) were differentially regulated during $P$. brassicae infection. The upregulation of methionine synthase and SAH hydrolase points to an increased ethylene production, whereas the downregulation of ADK reflects a suppression of the host defense during salt stress (Weretilnyk et al. 2001). In a reaction against Phytophthora megasperma fungal infection, rapid activation of SAH hydrolase transcription was observed in cultured parsley cells (Kawalleck et al. 1992). ADK plays a role in viral defense (Wang et al. 2003) and is a main enzyme of the adenine salvage pathway. A role for ADK also was suggested to interconvert cytokinin ribosides to the corresponding ribotides. The latter conversion can be a key mechanism in regulating the level of active cytokinins (Chen and Eckert 1977; Kwade et al. 2005; Laukens et al. 2003). Downregulation of this protein during Plasmodiophora brassicae infection may keep the elevated levels of active cytokinins high. This is consistent with the observation of an increased ARR5::GUS response in infected plants from 3 DAI on, as well as the increased endogenous iP and iPA content at 4 DAI.

\section{Energy metabolism.}

The RuBisCo LSU was upregulated during P. brassicae infection. This upregulation may point to an induced production of chlorophyll. The appearance of "green islands" at the sites of infection has been correlated previously with elevated levels of cytokinins (Jameson 2000). The fact that differentially regulated proteins are found that correspond to an altered cytokinin response (RuBisCo LSU or ADK) during P. brassicae infection correlates with our theory that cytokinins are present at the site of infection.

Another energy-related protein that is downregulated upon $P$. brassicae infection is fructose-bisphosphate aldolase. In a response of Arabidopsis to iron deficiency, the aldolase was upregulated. This was consistent with an increased carbon flow toward glycolysis (Thimm et al. 2001). The downregulation upon $P$. brassicae infection suggests a flow toward the production of glucose. This correlates with the fact that galls of P. brassicae act as a carbon sink (Evans and Scholes 1995). It is possible that this sink is induced by the high cytokinin level present at the infection site.

The dehydrogenase (IAR4) was upregulated in our analysis and also upon Agrobacterium tumefaciens infection (Zimmerman et al. 2004). It possibly acts on the conversion of indole-3-pyruvate to indole-3-acetyl-coenzyme A, which is a potential precursor of IAA amino-conjugates (LeClere et al. 2004). Therefore, it should be regarded as a protein with a dual function in hormone and energy metabolism. The observation of enhanced auxin gene responsiveness upon infection in this study and the $100 \%$ increase of IAA conjugates in Chinese cabbage at 6 DAI (Devos et al. 2005) may be indicative of increased IAA synthesis and a subsequent conjugation to IAAC. The latter may happen to avoid a potentially toxic accumulation of IAA in the infected plant (Devos et al. 2005). All these observations were made at 6 DAI and, because we noticed a differential IAR4 abundance at 4 DAI, it is possible that we observed here the initiation of these events.

\section{Cell rescue, defense, and virulence.}

It is striking that myrosinase was upregulated six times in the infected plants. Moreover, a myrosinase-binding protein also was upregulated. Myrosinase previously was reported to be upregulated in response to various other types of stress, including A. tumefaciens infection, nematodes, wounding, and salt stress (Zimmerman et al. 2004; Lee et al. 2004). It was noted that the symptom development and infection ratio of $P$. brassicae was lower in infected TU3 and TU8 mutants of Arabidopsis, which had altered glucosinolate (the breakdown product of myrosinase) patterns (Ludwig-Müller et al. 1999). In Brassica plants, indole-3-methyl glucosinolate is stored in the vacuole and can be released in the cytoplasm upon mechanical damage or pathogen attack, becoming available as a substrate for myrosinase and as a precursor in IAA biosynthesis. No differences in IAA levels were observed at 4 DAI; however, it is possible that IAA biosynthesis was upregulated upon $P$. brassicae infection as a consequence of indole-3methyl glucosinolate degradation, catalyzed by myrosinase. At later DAI, IAA triggered the DR5-directed response that is observed in this study, and auxin-related processes like cell division and expansion occurred on behalf of the propagation of the pathogen.

\section{Detoxification.}

During $P$. brassicae infection, cat3, GST, thioredoxin, and ferredoxin-nitrate reductase were upregulated. Cat3 was the protein most sensitive toward oxidative stress. It was upregulated during chilling (Prasad et al. 1994) and the mRNA levels of cat3 were higher during oxidative stress induced by paraquat or the fungal toxin cercosporin (Orendi et al. 2001). The expression of members of the GST multigene family were upregulated in Arabidopsis plants inoculated with an avirulent strain of Pseudomonas syringae pv. tomato (Lieberherr et al. 
2003), after aluminum stress (Ezaki et al. 2004), or by cell damage caused by Peronospora parasitica attack (Wagner et al. 2002). GSTs may be involved in the detoxification of auxin by conjugation (Marrs 1996). We found evidence for IAA accumulation caused by the conversion of methyl glucosinolate degradation, catalyzed by myrosinase. However, we did not detect altered levels of IAA. It is possible that GST was upregulated during Plasmodiophora brassicae infection to detoxify free IAA. No increase in the levels of IAA conjugates was observed at 4 DAI. It might be that this will occur at a later stage, as was observed by Devos and associates (2005).

Disulfide isomerase and peroxiredoxin were downregulated during $P$. brassicae infection. The molecular mass of the peroxiredoxin was lower than the predicted molecular mass of this protein. We found sequence homology to the catalytical subunit of the enzyme, which indicates that only this part was regulated differentially upon infection. In contrast with genome analysis, a proteome approach highlighted additional information of post-translational modifications that may be significant in light of the mechanisms by which $P$. brassicae controls plant defense. The fact that some proteins involved in oxidative stress were upregulated, whereas others were downregulated, indicates that the host plant defense on the level of oxidative stress was partially suppressed and partially induced.

\section{Cell differentiation and cytoskeleton.}

We showed that tubulins were downregulated upon infection with clubroot disease. These proteins also were downregulated in response to A. tumefaciens infection (Zimmerman et al. 2004). A complete disorganization of cell cytoplasm and a reorientation and loss of microtubules was seen during the incompatible interaction between soybean and Phytophthora sojae (Cahill et al. 2002). Downregulation of tubulin has consequences to the microtubule cytoskeleton and is supposed to be responsible for the loss of cell structure that is observed in the clubroot-infected cells (Mithen and Magrath 1992).

\section{Putative classification and unclassified proteins.}

Here we report on two major latex proteins that were upregulated during $P$. brassicae infection. The expression of major latex proteins was upregulated during nematode infection (Zimmerman et al. 2004).

The fact that PGIP was upregulated during clubroot disease may point to an induced defense reaction of the plant toward the pathogen. PGIPs are present in the cell walls of all plants examined to date and specifically inhibit endoPGs of fungi, but not those of plants or bacteria (Gomathi and Gnanamanickam 2004). Recently, it was shown that two tandemly duplicated PGIP genes were upregulated co-coordinately in Arabidopsis thaliana in response to Botrytis cinerea infection (Ferrari et al. 2003).

We showed that it was only the catalytic site, responsible for enzyme activity, of the pectin methylesterase that was upregulated during infection. The other part of the protein was a signal peptide that directs the protein to the cell wall (Gaffe et al. 1997). In plants, the pectin methylesterase plays an important role in cell wall metabolism during fruit ripening (Ray et al. 1988). In the plant bacterial and fungal pathogens Erwinia carotovora and Aspergillus niger, pectin methylesterase was involved in maceration and soft rotting, respectively, of the host tissue (Plastow 1988). The upregulation of pectin methylesterase may be directly linked with alterations in the cell wall to the pathogen's benefit. It already was suggested by Mithen and Magrath (1992) that cell-wall-degrading enzymes were produced during clubroot disease.

In our analysis, cystatin was upregulated during clubroot disease. In a previous study in which cystatin was overex- pressed in Arabidopsis thaliana, a resistant response to the nematode Rotylenchulus reniformis was observed (Urwin et al. 2000). A recombinant barley cystatin inhibited the growth of three plant-pathogenic fungi and a saprotrophic fungus (Martinez et al. 2003). Therefore, cystatin will be regarded as a defense protein of the host during $P$. brassicae infection.

The GABA transaminase was upregulated upon $P$. brassicae infection. During the growth of another biotrophic pathogen, Cladosporium fulvum within tomato, the GABA transaminase was appreciably higher during a compatible interaction than in the incompatible interaction. Probably, the fungus altered the physiology of the tomato to obtain a nitrogen source (Solomon and Oliver 2002). A similar role for GABA transaminase may exist during clubroot disease. It is possible that nitrogen is directed toward the plasmodia in a sink-dependent way that is induced by cytokinins.

\section{Other proteins.}

During $P$. brassicae infection, the $20 \mathrm{~S}$ proteasome was downregulated. Yeast mutants with defects in the different activities of the $20 \mathrm{~S}$ proteasome were sensitive to heat stress (Hilt and Wolf 1996). Therefore, a downregulation of this proteasome subunit may point to a disabled host defense reaction.

The GTP-binding nuclear protein from the RAN1 gene of $A$. thaliana was expressed in all meristematic areas. Here, we showed that the infection site of $P$. brassicae can be considered as a new meristematic region, because higher $C Y C B 1 ; 1-$ directed GUS activity was observed in the $P$. brassicaeinfected roots. The upregulation of RAN1 during infection shown in this study can be related to this observation. RAN1 played a key role in transporting the nuclear proteins responsible for suppression of auxin action and regulation in root tips (Kim et al. 2001). The upregulation of this protein in the infected tissue, as shown here, can be a presage for the enhanced auxin response upon early infection that was detected in this study.

Porins were localized on the bacteroid membranes in root nodules of Lotus japonicus (Wienkoop and Saalbach 2003) and Pisum sativum (Saalbach et al. 2002). It is possible that the putative porin that was upregulated during $P$. brassicae in this study may perform an equal function, thereby functioning as a bridge between the host and the pathogen.

The cytosolic cyclophilin encoded by the $A$. thaliana ROC3 gene was upregulated during $P$. brassicae infection. The expression of cyclophilin was shown to be induced by both biotic and abiotic stress, including $\mathrm{HgCl}_{2}$, viral infection, ethephon (an ethylene releaser), salicylic acid, abscisic acid, methyl jasmonate, salt stress, heat and cold shock, light, drought, wounding, and fungal infection (Romano et al. 2004). For this, ROC3 may be considered to be a protein involved in host defense.

\section{Proteins specifically related to $P$. brassicae.}

The elongation factor EF-2, a MutT/nudix family protein, a hypothetical protein, a putative ATP synthase, a nascent polypeptide-associated complex, the hypothetical nuclear RNA binding protein, and a putative heat shock protein were not previously encountered in other differential studies of biotic or abiotic stress in plants. It is premature to state that these proteins are uniquely related to clubroot disease because little genomic and proteomic data on stress in plants have been reported until now.

\section{Hypothetical model of events that occur in P. brassicae-infected Arabidopsis.}

Based on the results of this study, a hypothetical model on the metabolic events that occur upon clubroot disease in Arabidopsis thaliana is presented in Figure 5. In this study, we 
showed proteins that are involved in ROS, ethylene, or other plant defense which are either induced or suppressed upon infection. Despite the plant's defense attempt, it was unable to prevent $P$. brassicae development (Fig. 5, gray circle). It is known from literature that cytokinins are produced by the plasmodia (Müller and Hilgenberg 1986). Our study clearly confirms these results because a higher cytokinin level (iP and iPA) and gene responsiveness (ARR5::GUS) was detected in infected tissue. Moreover, ADK was downregulated, pointing toward an increased accumulation of active cytokinins. Because cytokinins have the ability to induce a sink in plant tissue (Mothes and Engelbrecht 1963), the newly formed plasmodia can be considered to act as a sink, and a new meristem is established. Supporting evidence for this hypothesis is that ARR5::GUS was upregulated first, followed by the upregulation of $C Y C B 1 ; 1::$ GUS and, eventually, the upregulation of DR5::GUS upon infection. The enhanced gene responsiveness to auxin in infected Arabidopsis plants suggests that plasmodia also act as a sink for auxin. At the proteome level, this was supported by the upregulation of myrosinase in particular, but also IAR4 and GST, three proteins that regulate IAA biosynthesis. From previous results, it is known that ethylene inhibits IAA transport (Morgan and Gausman 1966). We observed that three proteins involved in ethylene biosynthesis were differently regulated upon infection. This might level the content of ethylene (ADK, methionine synthase, SAH hydrolase) (Weretilnyk et al. 2001). In the clubroot-resistant mutant alh1, the altered cross talk of ethylene and auxin (Vandenbussche et al. 2003) might disturb the clubroot gall formation. From a previous study, it is known that carbohydrates are reallocated to the plasmodia (Evans and Scholes 1995). This study also revealed proteins that point toward an increased biosynthesis of carbohydrates in infected roots. Additionally, a putative source for nitrogen during clubroot disease was detected with the upregulation of GABA transaminase. A higher abundance of RuBisCo LSU was observed, indicating chlorophyll retention. The upregulation of the ATP synthase protein that was noted in our study suggests that higher energy levels are required in the infected plants. The susceptible reaction of Arabidopsis toward P. brassicae leads to cell division, cell expansion, and eventual cell degradation. We detected enhanced cell division in Arabidopsis using the $C Y C B 1 ; 1::$ GUS construct. We also noticed differentially regulated proteins that may be responsible for this altered cell morphology, including RAN1, tubulins, and pectin methylesterase.

\section{Conclusion.}

This study illustrates the power of a combined hormone and proteome approach in revealing metabolic events that regulate complex biological traits. Upon P. brassicae attack, the plant defense mechanism was counteracted by the pathogen and infection proceeded. In the cortex of the infected root and hypocotyl, the plasmodia produced cytokinins that trigger the re-initiation of cell division. Consequently, a new meristematic area was established, which acted as a sink for host IAA, carbohydrate, nitrogen, and energy in order to ensure further pathogen and gall development. Further development into a mature gall was the result of active cell division and elongation by a sustained meristematic activity without further differentiation.

\section{MATERIALS AND METHODS}

\section{Plant growth and inoculation.}

A. thaliana Col-0 (wild type, ARR5::GUS construct [D'Agostino et al. 2000] and DR5::GUS construct [Ulmasov et al. 1997]) and $A$. thaliana Ler with a labile $C Y C B 1 ; 1:: \mathrm{GUS}$ construct (Colón-Carmona et al. 1999) were sown in 35-by-21- by-5-cm pots containing moist compost (Asef, B.V.; Didam, The Netherlands) and placed in a growth chamber at $22^{\circ} \mathrm{C}$ and $60 \%$ relative humidity in a photoperiod of 16 and $8 \mathrm{~h}$ (L58W/77, Fluora, Osram; München, Germany). Infection with a resting

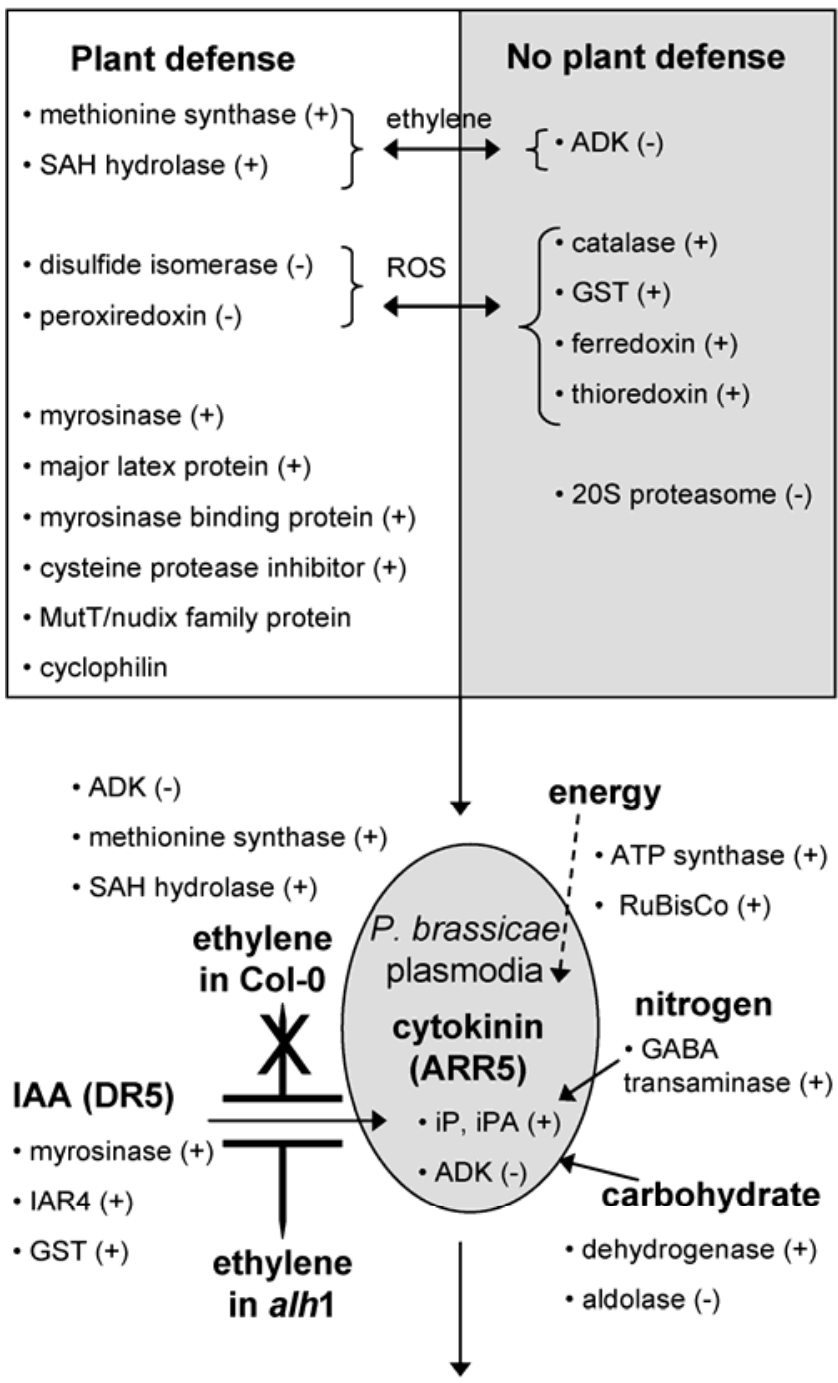

\begin{tabular}{|lll|}
\hline cell division & cell expansion & cell degradation \\
(CYCB1) & $\cdot$ tubulin $(-)$ & $\cdot \begin{array}{c}\text { pectin } \\
\text { methylesterase }(+)\end{array}$ \\
- RAN1 $(+)$ & PIPG1 $(+)$ &
\end{tabular}

Fig. 5. Hypothesis of plant processes upon Plasmodiophora brassicae infection of Arabidopsis thaliana Col-0 at 4 days after inoculation. Proteins that indicate plant defense (see white box) and proteins that point to a suppression of plant defense (see gray box) control the defense against $P$. brassicae. The plant is unable to defend itself and plasmodial development proceeds $(P$. brassicae plasmodia $=$ gray circle) . The plasmodia synthesize cytokinins that induce a sink for chlorophyll, nitrogen, carbohydrates, and indole-3-acetic acid (IAA). This process requires energy (dashed arrow). IAA transport that is necessary for accurate plasmodial development is not blocked by ethylene. When the cross talk of ethylene and auxin is altered, as in the alh 1 mutant, clubroot development is impaired. Upon a susceptible interaction, the newly formed plasmodial sink induces cell division, cell expansion, and, eventually, cell degradation. The proteins, reporter genes, and hormone compounds that are related to each process are presented (upregulated $[+]$ and downregulated [-] upon clubroot disease). Abbreviations: reaction oxygen species (ROS), Sadenosylhomocysteine (SAH), adenosine kinase (ADK), glutathione $S$-transferase (GST), dehydrogenase E1a-like subunit (IAR), 4-aminobutyrate aminotransferase (GABA), GTP-binding nuclear protein (RAN), polygalacturonase inhibiting protein (PIPG), isopentenyl adenine (iP), and isopentenyl adenosine (iPA). 
spore suspension of $P$. brassicae Woronin, isolated from clubroot-infected Brassica rapa roots obtained from Penyrheol, South Wales, was performed following the procedure of Mithen and Magrath (1992). The pathogenic nature of P. brassicae spore suspension was determined by the European Clubroot Differential (ECD) set according to Dixon (1976) and Toxopeus and associates (1986) and was found to be 16-2-12. Because clubroot disease occurs in soil, all plants examined were grown in soil. Two weeks after sowing, $1 \mathrm{ml}$ of a solution of $10^{6}$ spores per milliliter of $\mathrm{H}_{2} \mathrm{O}$ was added to the soil at the base of each plant. Control or noninfected plants were treated with $1 \mathrm{ml}$ of $\mathrm{H}_{2} \mathrm{O}$.

\section{Histochemical GUS assay.}

In all, $15 P$. brassicae-infected and 15 noninfected $A$. thaliana plants with the $C Y C B 1 ; 1:: G U S$, DR5::GUS, and ARR5::GUS constructs were grown. From 1 to 15 DAI, a histochemical GUS assay was performed in triplicate according to Jefferson and associates (1987). In brief, plant material was submerged in a $40 \mathrm{mM}$ 5-bromo-4-chloro-3-indolyl $\beta$-D-glucuronide solution made in a $50 \mathrm{mM}$ sodium phosphate buffer, $\mathrm{pH} 7.2$, with $10 \mathrm{mM} \mathrm{Na}_{2} \mathrm{EDTA}, 5 \mathrm{mM} \mathrm{K}_{4} \mathrm{Fe}(\mathrm{CN})_{6}$, and $1 \mathrm{mM}$ $\mathrm{K}_{3} \mathrm{Fe}(\mathrm{CN})_{6}$. A 1-min vacuum infiltration was carried out before the assay was set at $37^{\circ} \mathrm{C}$ in darkness overnight. Bright field pictures of $C Y C B 1 ; 1::$ GUS and ARR5::GUS were taken using a Nikon DXM1200 digital camera mounted on an Axioskop microscope (Zeiss; Jena, Germany). DR5::GUS was photographed with a digital camera (Olympus, C-4040ZOOM, Aartselaar, Belgium), using a stereomicroscope (Stemi SV11; Zeiss).

\section{Quantification of cytokinins and auxins.}

For both cytokinin (zeatin, DHZ, Z-N-G, ZR, DHZR, DHZN-G, ZR-P, DHZR-P, iP-G, iPA, and iPA-P) and auxin (IAA and IAA-conjugates) quantification, three samples, each of which included $50 \mathrm{P}$. brassicae-infected or 50 control $A$. thaliana Col-0, were harvested at 4 DAI. The fresh weight of the samples varied from 30 to $50 \mathrm{mg}$, corresponding to the actual mass of the harvested root system and the flanking $1 \mathrm{~cm}$ of hypocotyl. Hormone levels were analyzed combining solid phase extraction (Prinsen et al. 2000; Redig et al. 1996) and microliquid chromatography electrospray plus tandem mass spectrometry (Devos et al. 2005; Prinsen et al. 1998) using deuterated internal tracers (20 pmol each: Olchemim Int., Olomouc, Czech Republic for cytokinins and Cambridge Isotope Lab., Andover, MA, U.S.A. for auxins) for each compound analyzed.

\section{Mutant analysis.}

The reaction toward $P$. brassicae of the A. thaliana alh $1 \mathrm{mu}-$ tant (Vandenbussche et al. 2003) was compared with that of the A. thaliana Col-0. Three samples, each of which included 10 control or 10 infected alh 1 mutants, were grown in parallel with three samples of 10 control or 10 infected A. thaliana Col-0. NAA was added to the soil in order to try to rescue the alh 1 phenotype upon infection. Therefore, $10 \mu \mathrm{M}$ NAA was added to the soil of three times 10 control and 10 infected alh 1 mutants in parallel with three times 10 control and 10 infected A. thaliana Col-0. The infection ratio was used to score disease symptom development and the disease phenotype was described at 32 DAI. Pictures were taken with a digital camera (Olympus, C-4040ZOOM).

\section{Chemicals for proteome analysis.}

Immobilized pH gradient (IPG) buffer, Immobiline DryStrips, CHAPS (3-[(3-cholamidopropyl)-dimethyl-ammonio]-1-propanesulfonate), urea, $\beta$-mercaptoethanol, and glycerol were purchased from GE Healthcare (Roosendaal, The Netherlands). Acrylamide came from Bio-Rad (Nazareth, Belgium). Coomassie brilliant blue R-250 was purchased from ICN Biomedicals Inc. (Asse-Relegem, Belgium). Trypsin was bought from Roche (Brussels, Belgium). Thiourea was purchased from Fluka (Buchs, Switzerland), whereas acetone, methanol, acetic acid, and ethanol were purchased from Riedel-de Haën (Seelze, Germany). All other chemicals were purchased from Sigma (Bornem, Belgium).

\section{Sample preparation for proteomics.}

Noninfected and $P$. brassicae-infected plants were harvested at 4 DAI. The plants were washed carefully twice with $\mathrm{H}_{2} \mathrm{O}$ and roots and hypocotyls of the plants were transferred immediately to liquid nitrogen and stored at $-70^{\circ} \mathrm{C}$ until use. Each sample consisted of an independent pool of 250 to 300 plants with a fresh weight of approximately $100 \mathrm{mg}$. Three pools of plants were used for protein extraction of each condition (control and infected). Sample preparation was based on the procedure described by Damerval and associates (1986) and adjusted by Laukens and associates (2004). In brief, samples were ground in liquid nitrogen. The homogenate was suspended in $1 \mathrm{ml}$ of acetone $\left(-20^{\circ} \mathrm{C}\right)+10 \% \mathrm{vol} / \mathrm{vol}$ trichloroacetic acid $+0.07 \% \mathrm{vol} / \mathrm{vol} \beta$-mercaptoethanol and incubated overnight at $-20^{\circ} \mathrm{C}$. After centrifugation, $\left(15,000 \times g, 4^{\circ} \mathrm{C}, 10 \mathrm{~min}\right)$, the supernatant was removed, $1 \mathrm{ml}$ of ice-cold acetone $+0.07 \%$ $\mathrm{vol} / \mathrm{vol} \beta$-mercaptoethanol was added, and the samples were stored for $1 \mathrm{~h}$ at $-20^{\circ} \mathrm{C}$. The samples were centrifuged again (using the same conditions), and the pellet was air dried at room temperature and dispensed in $100 \mu \mathrm{l}$ of resolubilization buffer ( $2 \mathrm{M}$ thiourea, $7 \mathrm{M}$ urea, $0.5 \%$ vol/vol IPG buffer, $\mathrm{pH} 3$ to $10,65 \mathrm{mM}$ dithiothreitol [DTT], and $2 \% \mathrm{wt} / \mathrm{vol}$ CHAPS). Insoluble particles were removed by centrifugation $(20,000 \times$ $g, 4^{\circ} \mathrm{C}, 30 \mathrm{~min}$ ) and protein level was determined using the Bio-Rad RC-DC protein assay.

\section{DGE.}

2DGE was performed as described by Laukens and associates (2004). The samples were diluted with strip rehydration buffer ( $2 \mathrm{M}$ thiourea, $6 \mathrm{M}$ urea, $0.5 \% \mathrm{vol} / \mathrm{vol}$ IPG buffer, $\mathrm{pH} 3$ to $10,15 \mathrm{mM}$ DTT, $0.5 \% \mathrm{wt} / \mathrm{vol} \mathrm{CHAPS}$, and $0.001 \% \mathrm{wt} / \mathrm{vol}$ bromophenol blue) to $100 \mu \mathrm{g}$ of protein per $450 \mathrm{ml}$ for analytical 2DGE. The samples were applied on a 24-cm IPG strip ( $\mathrm{pH} 3$ to 10), which was incubated for $12 \mathrm{~h}$ in gel rehydration at $30 \mathrm{~V}$, in an IPGphor isoelectric focusing unit (GE Healthcare) and subsequently focused according to the following protocol: $1 \mathrm{~h}$ at $200 \mathrm{~V}, 1 \mathrm{~h}$ at $500 \mathrm{~V}, 1 \mathrm{~h}$ at $1,000 \mathrm{~V}, 30$-min gradient at 1,000 to $8,000 \mathrm{~V}$, and $52,000 \mathrm{Vh}$ at $8,000 \mathrm{~V}$. Isoelectric focusing was carried out at $20^{\circ} \mathrm{C}$ with the current limited to 50 $\mathrm{mA}$ strip $^{-1}$. Strips not immediately processed after the first dimension were stored at $-70^{\circ} \mathrm{C}$. Before transfer to the second dimension, strips were incubated for $15 \mathrm{~min}$ in $5 \mathrm{ml}$ of equilibration buffer (6 M urea, 30\% vol/vol glycerol, $2 \% \mathrm{wt} / \mathrm{vol}$ sodium dodecyl sulfate [SDS], $0.05 \mathrm{M}$ Tris-HCl, $\mathrm{pH} 8.8$, and $0.001 \% \mathrm{wt} / \mathrm{vol}$ bromophenol blue) supplemented with $1 \%$ $\mathrm{wt} / \mathrm{vol}$ DTT, followed by $15 \mathrm{~min}$ in $5 \mathrm{ml}$ of equilibration buffer supplemented with $4 \% \mathrm{wt} / \mathrm{vol}$ iodoacetamide. The second dimension was run on lab-cast 1-mm-thick SDS polyacrylamide gels $(12 \%)$ in an Ettan Dalt 6 electrophoresis tank (GE Healthcare, $\left.15^{\circ} \mathrm{C}\right)$ at $2.5 \mathrm{~W} \mathrm{gel}^{-1}(600 \mathrm{~V}, 400 \mathrm{~mA})$ for $30 \mathrm{~min}$ and further at $100 \mathrm{~W}(600 \mathrm{~V}, 400 \mathrm{~mA})$ until the dye front reached the gel border.

\section{Protein visualization and image analysis.}

Proteins were visualized by Coomassie staining (Neuhoff et al. 1985) and modified as follows. After 2DGE, proteins were fixed on the gel by fixing solution $(1.3 \% \mathrm{wt} / \mathrm{vol}$ phosphoric acid, 
$20 \% \mathrm{vol} / \mathrm{vol} \mathrm{MeOH}, 1 \mathrm{~h}$ ) and stained overnight (400 $\mathrm{ml}$ of $2 \%$ wt/vol phosphoric acid and $10 \% \mathrm{wt} / \mathrm{vol}$ ammonium sulfate in water $+5 \% \mathrm{wt} /$ vol Coomassie brilliant blue G-250 in water + $100 \mathrm{ml}$ of $\mathrm{MeOH})$. Gels were neutralized for $3 \mathrm{~min}$ in neutralizing solution ( $0.1 \mathrm{M}$ Tris-base in water and titrated to $\mathrm{pH} 6.5$ with phosphoric acid). Then, samples were washed with $25 \%$ vol/vol $\mathrm{MeOH}$ for less than $1 \mathrm{~min}$ and transferred to a stabilizing solution (20\% wt/vol ammonium sulfate). Gels were imaged with a bright-field Imagescanner (GE Healthcare). Image analysis was performed with ImageMaster Platinum software (version 5.0; GE Healthcare). Spots were detected automatically using the following parameters: smooth $=2$, saliency $=200$, and minimal area $=33$. After detection of the spots, artifacts were deleted manually. Three landmarks were included and the gel shown in Figure 4A was used as a reference gel before the spots of both conditions were automatically matched. A class report was made using the parameter "percentage volume," of which an average was calculated for control and infected treatments. The average of all spots which showed a statistically significant up- or downregulation of at least a factor 1.5 between controls and infected roots were selected for protein identification. All selected spots were verified manually.

\section{Protein identification.}

Proteins of interest were cut out manually and processed essentially as described by Shevchenko and associates (1996). In brief, the gel particles were washed extensively, using 100 $\mathrm{mM} \mathrm{NH} \mathrm{HCO}_{3}$ and acetonitril $(95 \% \mathrm{vol} / \mathrm{vol})$ alternately. The proteins were digested for $3 \mathrm{~h}$ with trypsin (Trypsin Gold, mass spectrometry grade; Promega, Leiden, The Netherlands). The peptides were concentrated and desalted using microcolumn C18 tips (PerfectPureTM C18 tip; Eppendorf; Hamburg, Germany). The peptides were eluted using a 1.2- $\mu$ l volume of a $50 \% \mathrm{vol} / \mathrm{vol}$ acetonitril: $0.1 \% \mathrm{vol} / \mathrm{vol}$ trifluor acetic acid solution saturated with $\alpha$-cyano-4-hydroxycinnamic acid and spotted directly on the MALDI target (OptiMaldi plate; Applied Biosystems; Lennik, Belgium). Peptide mass fingerprinting and peptide sequence analysis was performed on a MALDITOF-TOF instrument (4700 Proteomics Analyzer, Applied Biosystems). Peptide mass spectra and peptide fragmentation spectra of each sample were submitted for identification using a local search engine (Mascot version 1.9, Matrix Science) (Perkins et al. 1999). Public protein and DNA databases were used for identification using the latest updates available at the time of submission. All of the reported proteins had a relative Mascot score exceeding 99.99\% confidence (GPS explorer 2.0, Applied Biosystems).

\section{ACKNOWLEDGMENTS}

This work was financed by the Belgian Program on Interuniversity Attraction Poles (Prime Minister's Office, Science Programming) to D. Van Der Straeten, D. Inze, H. Van Oonckelen, and E. Prinsen and a BOF-NOI grant of the University of Antwerp and the Research council to E. Prinsen. M. Durmowicz is acknowledged for help with the practical work. Plasmodiophora brassicae inoculum was kindly given by S. Rolfe and J. Scholes of the University of Sheffield (U. K.). CYCB1;1::GUS, DR5::GUS, and ARR5::GUS seed were provided by P. Doerner of the University of Edinburgh (Scotland), T. J. Guilfoyle of the University of Missouri-Columbia (U. S. A.), and J. J. Kieber of the University of North Carolina (U. S. A.), respectively. ECD host plants were provided by D. Astley of the Genetic Resources Unit at Warwick HRI (United. K.). H. Slegers of the University of Antwerp (Belgium) is acknowledged for the use of the image scanner and S. Van Dongen of the University of Antwerp for statistical analysis.

\section{LITERATURE CITED}

Ando, S., Asano, T., Tsushima, S., Kamachi, S., Hagio, T., and Tabei, Y. 2005. Changes in gene expression of putative isopentenyltransferase during clubroot development in Chinese cabbage (Brassica rapa L.). Physiol. Mol. Plant Pathol. 67:59-67.

Angra-Sharma, R., and Sharma, D. K. 1999. Cytokinins in pathogenesis and disease resistance of Pyrenophora teres-barley and Dreschslera maydis-maize interactions during early stages of infection. Mycopathologia 148:87-95.

Butcher, D. N., El-Tigani, S., and Ingram, D. S. 1974. The role of indole glucosinolates in the clubroot disease of the Cruciferae. Physiol. Plant Pathol. 4:127-140.

Cahill, D., Rookes, J., Michalczyk, A., McDonald, K., and Drake, A. 2002. Microtubule dynamics in compatible and incompatible interactions of soybean hypocotyl cells with Phytophthora sojae. Plant Pathol. 51:629640.

Chen, C.-M., and Eckert, R. L. 1977. Phosphorylation of cytokinin by adenosine kinase from wheat germ. Plant Physiol. 59:443-447.

Colhoun, J. 1958. Club root disease of crucifers caused by Plasmodiophora brassicae Woron. In: Phytopathology Paper No. 3. Commonwealth Mycological Institute, Kew, England.

Colón-Carmona, A., You, R., Haimovitch-Gal, T., and Doerner, P. 1999. Spatio-temporal analysis of mitotic activity with a labile cyclin-GUS fusion protein. Plant J. 20:503-508.

D’Agostino, I. B., Deruère, J., and Kieber, J. J. 2000. Characterization of the response of the Arabidopsis response regulator gene family to cytokinin. Plant Physiol. 124:1706-1717.

Damerval, C., de Vienne, D., Zivy, M., and Thiellement, H. 1986. Technical improvements in two-dimensional electrophoresis increase the level of genetic variation detected in wheat-seedling proteins. Electrophoresis 7:52-54.

Dekhuijzen, H. M. 1980. The occurrence of free and bound cytokinins in clubroots and Plasmodiophora brassicae infected turnip tissue cultures. Physiol. Plant. 49:169-176.

Dekhuijzen, H. M. 1981. The occurrence of free and bound cytokinins in plasmodia of Plasmodiophora brassicae isolated from tissue cultures of clubroots. Plant Cell Rep. 1:18-20.

Dekhuijzen, H. M., and Overeem, J. C. 1971. The role of cytokinins in clubroot formation. Physiol. Plant Pathol. 1:151-161.

Devos, S., Vissenberg, K., Verbelen, J.-P., and Prinsen, E. 2005. Infection of Chinese cabbage by Plasmodiophora brassicae leads to a stimulation of plant growth: Impacts on cell wall metabolism and hormone balance. New Phytol. 166:241-250.

Dixon, G. R. 1976. Methods used in Western Europe and USA for testing Brassica seedling resistance to clubroot (Plasmodiophora brassicae). Plant Pathol. 25:129-134.

Evans, J. L., and Scholes, J. D. 1995. How does clubroot alter the regulation of carbon metabolism in its host? Asp. Appl. Biol. 42:125-132.

Ezaki, B., Suzuki, M., Motoda, H., Kawamura, M., Nakashima, S., and Matsumoto, H. 2004. Mechanism of gene expression of Arabidopsis glutathione $S$-transferase, AtGST1, and AtGST11 in response to aluminum stress. Plant Physiol. 134:1672-1682.

Ferrari, S., Vairo, D., Ausubel, F. M., Cervone, F., and De Lorenzo, G. 2003. Tandemly duplicated Arabidopsis genes that encode polygalacturonase-inhibiting proteins are regulated coordinately by different signal transduction pathways in response to fungal infection. Plant Cell 15:93106.

Gaffe, J., Tiznado, M. E., and Handa, A. K. 1997. Characterization and functional expression of a ubiquitously expressed tomato pectin methylesterase. Plant Physiol. 114:1547-1556.

Gomathi, V., and Gnanamanickam, S. S. 2004. Polygalacturonase-inhibiting proteins in plant defense. Curr. Sci. 87:1212-1217.

Grsic-Rausch, S., Kobelt, P., Siemens, J. M., Bischoff, M., and LudwigMüller, J. 2000. Expression and localization of nitrilase during symptom development of the clubroot disease in Arabidopsis. Plant Physiol. 122:369-378

Hansen, C. E. R., Flengsrud, R., and Kopperud, C. 1994. Two-dimensional gel electrophoresis of proteins in healthy roots and clubroots of Brassica oleracea. Acta Agric. Scand. Sect. B Soil Plant Sci. 44:123-128.

Hilt, W., and Wolf, D. H. 1996. Proteasomes: Destruction as a program. Trends Biochem. Sci. 21:96-102.

Himanen, K., Boucheron, E., Vanneste, S., de Almeida Engler, J., Inzé, D., and Beeckman, T. 2002. Auxin-mediated cell cycle activation during early lateral root initiation. Plant Cell 14:2339-2351.

Ingram, D. S., and Tommerup, I. C. 1972. The life history of Plasmodiophora brassicae Woron. Proc. R. Soc. Lond. Ser. B 180:103-112.

Ito, S., Tanaka, S., Miyanaga, C., Takabayashi, S., Yano, S., and KameyaIwaki, M. 1996. Constitutive and inducible proteins in the root of Chinese cabbage infected with Plasmodiophora brassicae. J. Phytopathol. 144:89-95.

Jameson, P. 2000. Cytokinins and auxins in plant-pathogen interactions An overview. Plant Growth Regul. 32:369-380.

Jefferson, R. A., Kavanagh, T. A., and Bevan, M. W. 1987. GUS fusions: 
$\beta$-glucuronidase as a sensitive and versatile gene fusion marker in higher plants. EMBO (Eur. Mol. Biol. Organ.) J. 6:3901-3907.

Kavanagh, J. A., and Williams, P. H. 1981. Indole auxins in Plasmodiophora infected cabbage roots and hypocotyls. Trans. Br. Mycol. Soc. 77:125-129

Kawalleck, P., Plesch, G., Hahlbrock, K., and Somssich, I. E. 1992. Induction by fungal elicitor of $S$-adenosyl-L-methionine synthetase and $S$ adenosyl-L-homocysteine hydrolase mRNA in cultured cells and leaves of Petroselium crispum. Proc. Natl. Acad. Sci. U.S.A. 89:4713-4717.

Kim, S.-H., Arnold, D., Lloyd, A., and Roux, S. J. 2001. Antisense expression of an Arabidopsis ran binding protein renders transgenic roots hypersensitive to auxin and alters auxin-induced root growth and development by arresting mitotic progress. Plant Cell 13:2619-2630.

Kwade, Z., Światek, A., Azmi, A., Goossens, A., Inzé, D., Van Onckelen, H., and Roef, L. 2005. Identification of four adenosine kinase isoforms in tobacco BY-2 cells and their putative role in the cell cycle-regulated cytokinin metabolism. J. Biol. Chem. 280:17512-17519.

Laukens, K., Lenobel, R., Strnad, M., Van Onckelen, H., and Witters, E. 2003. Cytokinin affinity purification and identification of a tobacco BY2 adenosine kinase. FEBS (Fed. Eur. Biochem. Soc.) Lett. 533:63-66.

Laukens, K., Deckers, P., Esmans, E., Van Onckelen, H., and Witters, E. 2004. Construction of a two-dimensional gel electrophoresis protein database for the Nicotiana tabacum cv. Bright Yellow-2 cell suspension culture. Proteomics 4:720-727.

LeClere, S., Rampey, R. A., and Bartel, B. 2004. IAR4, a gene required for auxin conjugate sensitivity in Arabidopsis, encodes a pyruvate dehydrogenase E1 $\alpha$ homolog. Plant Physiol. 135:989-999.

Lee, S., Lee, F. J., Yang, F. J., Lee, J. F., Park, A. R., Song, W. H., and Park, O. K. 2004. Proteomic identification of annexins, calcium-dependent membrane binding proteins that mediate osmotic stress and abscisic acid signal transduction in Arabidopsis. Plant Cell 16:1378-1391.

Lieberherr, D., Wagner, U., Dubuis, P.-H., Métraux, J.-P., and Mauch, F. 2003. The rapid induction of glutathione $S$-transferases AtGSTF2 and AtGSTF6 by avirulent Pseudomonas syringae is the result of combined salicylic acid and ethylene signaling. Plant Cell Physiol. 44:750-757.

Ludwig-Müller, J., Bendel, U., Thermann, P., Ruppel, M., Epstein, E., and Hilgenberg, W. 1993. Concentrations of indole-3-acetic acid in plants of tolerant and susceptible varieties of Chinese cabbage infected with Plasmodiophora brassicae Woron. New Phytol. 125:763-769.

Ludwig-Müller, J., Thermann, P., Pieper, K., and Hilgenberg, W. 1994. Peroxidase and chitinase isoenzyme activities during root infection of Chinese cabbage with Plasmodiophora brassicae Woron. Physiol. Plant. 90:661-670.

Ludwig-Müller, J., Epstein, E., and Hilgenberg, W. 1996. Auxin-conjugate hydrolysis in Chinese cabbage: Characterization of an amidohydrolase and its role during infection with clubroot disease. Physiol. Plant. 97:627-634

Ludwig-Müller, J., Pieper, K., Ruppel, M., Cohen, J. D., Epstein, E., Kiddle, G., and Bennett, R. 1999. Indole glucosinolate and auxin biosynthesis in Arabidopsis thaliana (L.) Heynh. glucosinolate mutants and the development of clubroot disease. Planta 208:409-419.

Marrs, K. A. 1996. The functions and regulation of glutathione S-transferases in plants. Annu. Rev. Plant Physiol. Plant Mol. Biol. 47:127158

Martinez, M., Lopez-Solanilla, E., Rodriguez-Palenzuela, P., Carbonero, P., and Diaz, I. 2003. Inhibition of plant-pathogenic fungi by the barley cystatin Hv-CPI (gene Icy) is not associated with its cysteine-proteinase inhibitory properties. Mol. Plant-Microbe Interact. 16:876-883.

Mithen, R., and Magrath, R. 1992. A contribution to the life history of Plasmodiophora brassicae: Secondary plasmodia development in root galls of Arabidopsis thaliana. Mycol. Res. 96:877-885.

Mok, D. W. S., and Mok, M. C. 2001. Cytokinin metabolism and action. Annu. Rev. Plant Physiol. Plant Mol. Biol. 52:89-118.

Morgan, P. W., and Gausman, H. W. 1966. Effects of ethylene on auxin transport. Plant Physiol. 41:45-52.

Mothes, K., and Engelbrecht, L. 1963. On the activity of a kinetin-like root factor. Life Sci. 11:852-857.

Mousdale, D. M. A. 1981. Endogenous indolyl-3-acetic acid and pathogen-induced plant growth disorders: Distinction between hyperplasia and neoplastic development. Experientia 37:972-973.

Müller, P., and Hilgenberg, W. 1986. Isomers of zeatin and zeatin riboside in clubroot tissue: Evidence for trans-zeatin biosynthesis by Plasmodiophora brassicae. Physiol. Plant. 66:245-250.

Neuhaus, K., Grsic-Rausch, S., Sauerteig, S., and Ludwig-Müller, J. 2000. Arabidopsis plants transformed with nitrilase 1 or 2 in antisense direction are delayed in clubroot development. J. Plant Physiol. 156:756761

Neuhoff, V., Stamm, R., and Eibl, H. 1985. Clear background and highly sensitive protein staining with Coomassie Blue dyes in polyacrylamide gels: A systematic analysis. Electrophoresis 6:427-448.
Oh, I. S., Park, A. R., Bae, M. S., Kwon, J. S., Kim, Y. S., Lee, J. E., Kang, N. Y., Lee, S., Cheong, H., and Parka, O. K. 2005. Secretome analysis reveals an Arabidopsis lipase involved in defense against Alternaria brassicicola. Plant Cell 17:2832-2847.

Orendi, G., Zimmermann, P., Baar, C., and Zentgraf, U. 2001. Loss of stress-induced expression of catalase 3 during leaf senescence in Arabidopsis thaliana is restricted to oxidative stress. Plant Sci. 161:301-314.

Perkins, D. N., Pappin, D. J., Creasy, D. M., and Cottrell, J. S. 1999. Probability-based protein identification by searching sequence databases using mass spectrometry data. Electrophoresis 20:3551-3567.

Plastow, G. S. 1988. Molecular cloning and nucleotide sequence of the pectin methyl esterase gene of Erwinia chrysanthemi B374. Mol. Microbiol. 2:247-254.

Prasad, T. K., Anderson, M. D., Martin, B. A., and Stewart, C. R. 1994. Evidence for chilling-induced oxidative stress in maize seedlings and a regulatory role for hydrogen peroxide. Plant Cell 6:65-74.

Prinsen, E., Van Dongen, W., Esmans, E. L., and Van Onckelen, H. A. 1998. Micro and capillary liquid chromatography-tandem mass spectrometry: A new dimension in phytohormone research. J. Chromatogr. A 826:25-37.

Prinsen, E., Van Laer, S., Öden, S., and Van Onckelen, H. 2000. Auxin Analysis. Pages 49-65 in: Methods in Molecular Biology, vol. 141: Plant Hormone Protocols. G. A. Tucker and J. A. Roberts, eds. Humana Press, Totowa, NJ, U.S.A.

Puzio, P. S., Newe, M., Grymaszewska, G., Ludwig-Müller, J., and Grundler, F. M. W. 2000. Plasmodiophora brassicae-induced expression of pyk20, an Arabidopsis thaliana gene with glutamine-rich domain. Physiol. Mol. Plant Pathol. 56:79-84.

Raa, J. 1971. Indole-3-acetic acid levels and the role of indole-3-acetic acid oxidase in the normal root and club-root of cabbage. Physiol. Plant. 25:130-134.

Ray, J., Knapp, J., Grierson, D., Bird, C., and Schuch, W. 1988. Identification and sequence determination of a cDNA clone for tomato pectinesterase. Eur. J. Biochem. 174:119-124.

Redig, P., Schmülling, T., and Van Onckelen, H.A. 1996. Analysis of cytokinin metabolism in ipt transgenic tobacco by liquid chromatographytandem mass spectrometry. Plant Physiol. 112:141-148.

Romano, P. G. N., Horton, P., and Gray, J. E. 2004. The Arabidopsis cyclophilin gene family. Plant Physiol. 134:1268-1282.

Saalbach, G., Erik, P., and Wienkoop, S. 2002. Characterization by proteomics of peribacteroid space and peribacteroid membrane preparations from pea (Pisum sativum) symbiosomes. Proteomics 2:325-337.

Schoof, H., Zaccaria, P., Gundlach, H., Lemcke, K., Rudd, S., Kolesov, G., Arnold, R., Mewes, H. W., and Mayer, K. F. X. 2002. MIPS Arabidopsis thaliana Database (MAtDB): An integrated biological knowledge resource based on the first complete plant genome. Nucleic Acids Res. 30:91-93

Shevchenko, A., Wilm, M., Vorm, O., and Mann, M. 1996. Mass spectrometric sequencing of proteins from silver stained polyacrylamide gels. Anal. Chem. 68:850-858.

Siemens, J., Nagel, M., Ludwig-Müller, J., and Sacristán, M. D. 2002. The interaction of Plasmodiophora brassicae and Arabidopsis thaliana: Parameters for disease quantification and screening of mutant lines. J. Phytopathol. 150:592-605.

Solomon, P. S., and Oliver, R. P. 2002. Evidence that gamma-aminobutyric acid is a major nitrogen source during Cladosporium fulvum infection of tomato. Planta 214:414-420.

Stals, H., and Inzé, D. 2001. When plant cells decide to divide. Trends Plant Sci. 6:359-364.

Takahashi, H., Takita, K., Kishimoto, T., Mitsui, T., and Hori, H. 2002. $\mathrm{Ca}^{2+}$ is required by clubroot resistant turnip cells for transient increases in PAL activity that follow inoculation with Plasmodiophora brassicae. J. Phytopathol. 150:529-535

Thimm, O., Essigmann, B., Kloska, S., Altmann, T., and Buckhout, T. J. 2001. Response of Arabidopsis to iron deficiency stress as revealed by microarray analysis. Plant Physiol. 127:1030-1043.

Toxopeus, H., Dixon, G. R., and Mattusch, P. 1986. Physiological specialization in Plasmodiophora brassicae: An analysis by international experimentation. Trans. Br. Mycol. Soc. 87:279-287.

Ulmasov, T., Murfett, J., Hagen, G., and Guilfoyle, T. J. 1997. Aux/lAA proteins repress expression of reporter genes containing natural and highly active synthetic auxin response elements. Plant Cell 9:1963-1971.

Urwin, P. E., Levesley, A., McPherson, M. J., and Atkinson, H. J. 2000. Transgenic resistance to the nematode Rotylenchulus reniformis conferred by Arabidopsis thaliana plants expressing proteinase inhibitors. Mol. Breed. 6:257-264.

Vandenbussche, F., Smalle, J., Le, J., Saibo, N. J. M., De Paepe, A. Chaerle, L., Tietz, O., Smets, R., Laarhoven, L. J. J., Harren, F. J. M. Van Onckelen, H., Palme, K., Verbelen, J.-P., and Van Der Straeten, D. 
2003. The Arabidopsis mutant alh1 illustrates a cross talk between ethylene and auxin. Plant Physiol. 131:1228-1238.

Wagner, U., Edwards, R., Dixon, D. P., and Mauch, F. 2002. Probing the diversity of the Arabidopsis glutathione $S$-transferase gene family. Plant Mol. Biol. 49:515-532.

Wang, H., Hao, L., Shung, C. Y., Sunter, G., and Bisaro, D. M. 2003. Adenosine kinase is inactivated by geminivirus AL2 and L2 proteins. Plant Cell 15:3020-3032.

Wasinger, V. C., Cordwell, S. J., Cerpa-Poljak, A., Yan, J. X., Gooley, A A., Wilkins, M. R., Duncan, M. W., Harris, R., Williams, K. L., and Humphery-Smith, I. 1995. Progress with gene-product mapping of the Mollicutes: Mycoplasma genitalium. Electrophoresis 16:1090-1094.

Weretilnyk, E. A., Alexander, K. J., Drebenstedt, M., Snider, J. D., Summers, P. S., and Moffatt, B. A. 2001. Maintaining methylation activities during salt stress. The involvement of adenosine kinase. Plant Physiol. 125:856-865.
Wienkoop, S., and Saalbach, G. 2003. Proteome analysis. Novel proteins identified at the peribacteroid membrane from Lotus japonicus root nodules. Plant Physiol. 131:1080-1090.

Xue, J., Jørgensen, M., Pihlgren, U., and Rask, L. 1995. The myrosinase gene family in Arabidopsis thaliana: Gene organization, expression and evolution. Plant Mol. Biol. 27:911-922.

Zimmermann, P., Hirsch-Hoffmann, M., Hennig, L., and Gruissem, W. 2004. GENEVESTIGATOR. Arabidopsis microarray database and analysis toolbox. Plant Physiol. 136:2621-2632.

\section{AUTHOR-RECOMMENDED INTERNET RESOURCES}

The MIPS A. thaliana Genome database: mips.gsf.de/proj/thal/db

University of Antwerp-Centre for Proteome Analysis Arabidopsis thaliana proteome database: www.pdata.ua.ac.be/arabidopsis.thaliana 